\title{
CARACTERIZAÇÃO MORFOLÓGICA DE PERFIS DE SOLO DE UM ESTABELECIMENTO AGRÍCOLA FAMILIAR DO ASSENTAMENTO PIMENTEIRA, SÃO JOÃO DO ARAGUAIA-PA
}

\author{
Sâmia Alves Lopes'; Suellen Souza Gomes²; Aline De Jesus Franco³; Andréa Hentz de \\ Mello ${ }^{4}$; Gustavo Ferreira De Oliveira ${ }^{5}$. \\ 1Universidade Federal do Sul e Sudeste do Pará (UNIFESSPA), Marabá, Pará, Brasil, samia-always7@hotmail.com \\ ¿UNIFESSPA, Marabá, Pará, Brasil, sumellody@hotmail.com \\ 3UNIFESSPA, Marabá, Pará, Brasil, k_line5@hotmail.com \\ 4UNIFESSPA, Marabá, Pará, Brasil, andreahentz@unifesspa.edu.br \\ 5Universidade do Estado de Santa Catarina, Lages, Santa Catarina, Brasil, gf.oliveira90@hotmail.com
}

\begin{abstract}
RESUMO: Vários estudos preocuparam-se em investigar as relações existentes entre os atributos do solo e as diferentes condições ambientais nas quais estão inseridos. A caracterização morfológica dos solos permite resultados importantes nesse âmbito. Assim, o objetivo do trabalho foi avaliar a caracterização morfológica de três perfis de solo. Este trabalho foi realizado entre os dias 12 a 16 de agosto de 2013 em um estabelecimento de produção familiar do Assentamento Pimenteira, São João do Araguaia-PA. A metodologia utilizada foi a de abertura de trincheiras em três áreas distintas (área de pasto, área de cultivo de mandioca e área de mata secundária) para posterior análise morfológica e caracterização do solo até o $2^{0}$ nível categórico conforme o Sistema Brasileiro de Classificação de Solos (SiBCS). Os resultados demonstraram que a textura do solo foi semelhante em ambas as áreas. A fração argila foi dominante em todos os solos analisados. Os principais atributos morfológicos e físicos são a presença de mosqueamento associado a cores mais brunadas escura, avermelhada, amarelado e acinzentado claro, a textura argilosa, a estrutura em bloco subangular e a presença de plintita. Os perfis de solo apresentaram, em geral, horizontes diagnóstico B Plíntico.
\end{abstract}

PALAVRAS-CHAVE: Atributos morfológicos, Frações granulométricas, Plintossolo.

\section{MORPHOLOGICAL CHARACTERIZATION OF SOIL PROFILES OF A FAMILY FARM IN THE PIMENTEIRA SETTLEMENT, SÃO JOÃO DO ARAGUAIA-PA}

ABSTRACT: Several studies have focused on investigating the relationships between soil attributes and the different environmental conditions in which they are inserted. The morphological characterization of the soils allows important results in this area. Thus, the objective of this work was to evaluate the morphological characterization of three soil profiles. This work was carried out from August 12 to 16, 2013 in a family production establishment of the Pimenteira Settlement, São João do Araguaia-PA. The methodology used was to open trenches in three different areas (pasture area, cassava cultivation area 
and secondary forest area) for later morphological analysis and characterization of the soil up to the 10 categorical level according to the Brazilian Soil Classification System (SBCS). The results showed that the soil texture was similar in both areas. The clay fraction was dominant in all analyzed soils. The main morphological and physical attributes are the presence of mottling associated with more darkish, reddish, yellowish and light grayish hues, the clay texture, the subangular block structure and the presence of plinthite. The soil profiles presented, in general, diagnostic horizons B Plinthic.

KEY WORDS: Attributes, Granulometric fractions, Plenosol.

\section{CARACTERIZACIÓN MORFOLÓGICA DE PERFILES DE SOLO DE UN ESTABLECIMIENTO AGRÍCOLA FAMILIAR DEL ASENTAMIENTO PIMIENTE, SAN JUAN DEL ARAGUAIA-PA}

RESUMEN: Varios estudios se preocuparon en investigar las relaciones existentes entre los atributos del suelo y las diferentes condiciones ambientales en las cuales están insertados. La caracterización morfológica de los suelos permite resultados importantes en este ámbito. Así, el objetivo del trabajo fue evaluar la caracterización morfológica de tres perfiles de suelo. Este trabajo fue realizado entre los días 12 a 16 de agosto de 2013 en un establecimiento de producción familiar del Asentamiento Pimente, São João do AraguaiaPA. La metodología utilizada fue la de apertura de trincheras en tres áreas distintas (área de pastoreo, área de cultivo de mandioca y área de mata secundaria) para posterior análisis morfológico y caracterización del suelo hasta el 20 nivel categórico conforme al Sistema Brasileño de Clasificación de Suelos (SiBCS). Los resultados demostraron que la textura del suelo fue similar en ambas áreas. La fracción arcilla fue dominante en todos los suelos analizados. Los principales atributos morfológicos y físicos son la presencia de mosqueamiento asociado a colores más bruñidos oscura, rojiza, amarillento y grisáceo claro, la textura arcillosa, la estructura en bloque subangular y la presencia de plintita. Los perfiles de suelo presentaron, en general, horizontes diagnóstico B Plíntico.

PALABRAS CLAVE: Atributos morfológicos, Fracciones granulométricas, Plintossolo.

O solo constitui a superfície inconsolidada que recobre as rochas e mantém a vida animal e vegetal da Terra. É resultado de um processo de relações física, química e biológica que resultam da ação de vários fatores de formação como: material de origem, o relevo, clima, organismos e tempo, todos estes fatores integram a fração mineral do solo (ZIMBACK, 2003). 
Na Amazônia, grande parte dos solos encontram-se degradados devido aos processos de ocupação que modificaram os sistemas naturais, principalmente com a urbanização e atividade agropecuária baseada em práticas de manejo inadequadas.

As atividades de exploração nos solos dessa região devem ser cuidadosamente planejadas e as práticas de conservação devem ser aplicadas desde o início para preservar o potencial produtivo do solo para as gerações futuras (MULLER et al., 2001).

Nesse contexto, o estudo dos solos se mostra relevante, sendo a caracterização morfológica um importante subsídio de entendimento. Para Prado (1991), o estudo da morfologia do solo é precípuo, uma vez que através dele se faz o julgamento dos diversos aspectos morfológicos visando à classificação do solo para posterior aproveitamento dos conhecimentos nas práticas agrícolas e estudo de gênese.

Tendo em vista que o solo é o suporte de toda a produção vegetal, que por sua vez suporta a vida animal, e que por isso é imprescindível para as atividades agrícolas, e que a caracterização deste permite 0 seu melhor aproveitamento, haja vista a aptidão agrícola com que pode ser caracterizado e as práticas de manejo e conservação que podem ser aplicadas, que se conduziu o presente estudo. trabalho teve como objetivo caracterizar morfologicamente três perfis de solo em diferentes condições ambientais em uma unidade familiar do Assentamento Pimenteira, São João do Araguaia-PA.

Este trabalho foi realizado entre os dias 12 e 16 de agosto de 2013 no Assentamento Pimenteira, no município de São João do Araguaia, durante o Estágio de Campo Obrigatório do curso de Agronomia da Faculdade de Ciências Agrárias de Marabá.

- assentamento localiza-se na rodovia Transamazônica, nas coordenadas UTM $=E=727918,861$ e $\mathrm{N}=$ 9397353,232, município de São João do Araguaia em uma área denominada anteriormente de Fazenda Primavera. A cobertura vegetal predominante no assentamento são as arbóreas de médio/longo porte. A temperatura média anual é de $26,3^{\circ} \mathrm{C}$ (SEMA, 2009). 
A unidade familiar apresenta grande diversidade biológica, tendo flora e microfauna abundante. A reprodução de espécies de interesse do agricultor em áreas novas ou deterioradas em conjunto com outras espécies que venham favorecer o solo, abundância de matérias orgânicas bem como a diversidade de espécies na área propiciaram ao modelo de SAF.

A metodologia utilizada foi a de abertura de trincheiras em três áreas diferentes dentro do lote para a análise morfológica e caracterização do solo. As áreas foram escolhidas de forma a contemplar a diversidade de ambientes do lote. Desta forma, foram selecionadas áreas de pasto, cultivo de mandioca e de mata secundária, limitadas e apontadas pelo agricultor familiar.

As tricheiras de profundidade de 1,50 metros foram abertas com o auxílio de alavanca, cavadeira e pá reta. As seções dos três perfis foram identificadas, medidas com trena e separadas em folhas de jornal. As camadas do perfil de solo foram separadas com base na apresentação da sua coloração. Também foram observadas características inerentes ao solo, tais como: espessura, estrutura, cerosidade, plasticidade, presença ou ausência de cascalhos, mosqueamentos, plintita e concreções de ferro. Aliados a essas características, foram consideradas ainda as características referentes ao relevo, localização, vegetação, e topografia, de forma a auxiliar nas conclusões dos resultados obtidos com a caracterização morfológica dos perfis de solo.

A análise da textura foi feita pelo método da pipeta com água, baseada na sensação ao tato das amostras de solo com as mãos e com auxílio do Triângulo Textural de Solos (EMBRAPA, 2006). Neste estudo não foram realizadas análises laboratoriais dos atributos químicos e físicos do solo estudado, de modo que o solo foi classificado até o segundo nível categórico. A identificação dos horizontes e a descrição morfológica foram realizadas conforme o manual de descrição e coleta de solo no campo (LEMOS, 2005) e o solo foi classificado segundo os critérios de classificação do Sistema Brasileiro de Classificação de Solos (EMBRAPA, 2006). 
As diferentes áreas estudadas apresentaram solos com grande teor de argila na maior parte das seções e em profundidade elevando-se o teor de silte. Os perfis de solo das Áreas de Pasto e de Cultivo de Mandioca apresentam horizontes subsuperficiais (B e/ou C) com cores indicativas da presença de material plíntico e do processo de plintitização (EMBRAPA, 2006), com mosqueados vermelhos e vermelho-amarelados em quantidade abundante e de contraste proeminente em relação à cor de fundo (SANTOS et al., 2005) e com cores variegadas.

A fauna edáfica é mais abundante na Área de Floresta Secundária, que também é a área com maior umidade, e por seguinte na Área de cultivo de mandioca, propiciadas pela cobertura vegetal, enquanto que na área de pasto, percebe-se pouca interação da fauna edáfica com o solo.

primeiro perfil de solo foi denominado de Área de Pasto. Foram diferenciadas quatro seções: Ac, Bi, Cg e
Cp (Figura 1 e Tabela 1), dentre as quais a primeira apresentou uma coloração acinzentada. A fração argila foi dominante nas duas primeiras seções do perfil variando de $60 \%$ a $70 \%$ em relação à areia, com coloração amarelada na segunda seção. Na terceira seção houve presença de cascalho, com textura de $80 \%$ de argila e $20 \%$ de silte, com coloração amarela escura. Na quarta seção nota-se um arranjamento de cores amarelas, brancas, laranjas e vermelhas, além de pequenas concreções de óxidos de ferro característicos da plintita. A fração de argila é de $20 \%$ e a de silte $80 \%$, ocorrendo uma mudança abrupta da terceira seção para a quarta. 0 horizonte Ac foi classificado como A chernozêmico, o horizonte Bi como um B incipiente, o horizonte $\mathrm{Cg}$ como horizonte C glei, e o horizonte Cp como horizonte $\quad$ plíntico. 
Tabela 1. Caracterização morfológica de um perfil de solo em área de pasto no assentamento Pimenteira, São João do Araguaia-PA.

\begin{tabular}{|c|c|c|c|c|c|}
\hline \multicolumn{6}{|c|}{ Área de Pasto - Plintossolo Háplico } \\
\hline Horiz. & $\begin{array}{l}\text { Profund. } \\
(\mathrm{cm})\end{array}$ & Cor & Textura & Estrutura & Consistência \\
\hline$A C$ & $0-35 \mathrm{~cm}$ & $10 Y R 5 / 2$ & $\begin{array}{l}\text { Muito argilosa, } \\
\text { moderadamente } \\
\text { pedregoso }\end{array}$ & $\begin{array}{l}\text { Moderado a médio, } \\
\text { blocos angulares a } \\
\text { blocos subangulares. }\end{array}$ & $\begin{array}{c}\text { Plástica, ligeiramente } \\
\text { pegajosa, macia, friável. }\end{array}$ \\
\hline $\mathrm{Bi}$ & $35-55 \mathrm{~cm}$ & 10 YR 6/4 & $\begin{array}{l}\text { Argilosa, } \\
\text { moderadamente } \\
\text { pedregoso }\end{array}$ & $\begin{array}{l}\text { Moderado a médio, } \\
\text { blocos angulares a } \\
\text { blocos subangulares. }\end{array}$ & $\begin{array}{c}\text { Muito plástica, muito } \\
\text { pegajosa, macia, friável. }\end{array}$ \\
\hline $\mathrm{Cg}$ & $55-98 \mathrm{~cm}$ & $10 Y R 6 / 6$ & $\begin{array}{l}\text { Muito argilosa, } \\
\text { moderadamente } \\
\text { pedregoso }\end{array}$ & $\begin{array}{c}\text { Médio a forte, granular } \\
\text { blocos angulares a } \\
\text { subangulares. }\end{array}$ & $\begin{array}{l}\text { Muito plástica, muito } \\
\text { pegajosa, friável. }\end{array}$ \\
\hline $\mathrm{Cp}$ & $98-150 \mathrm{~cm}$ & 7,5 YR 6/7 & Franco siltosa. & $\begin{array}{c}\text { Médio a forte, blocos } \\
\text { angulares a blocos } \\
\text { subangulares, laminar. }\end{array}$ & $\begin{array}{c}\text { Pegajosa, não plástica, } \\
\text { macia, friável. }\end{array}$ \\
\hline
\end{tabular}

Figura 1. Perfil de solo e camadas dos horizontes em área de pasto no assentamento Pimenteira, São João do Araguaia-PA.
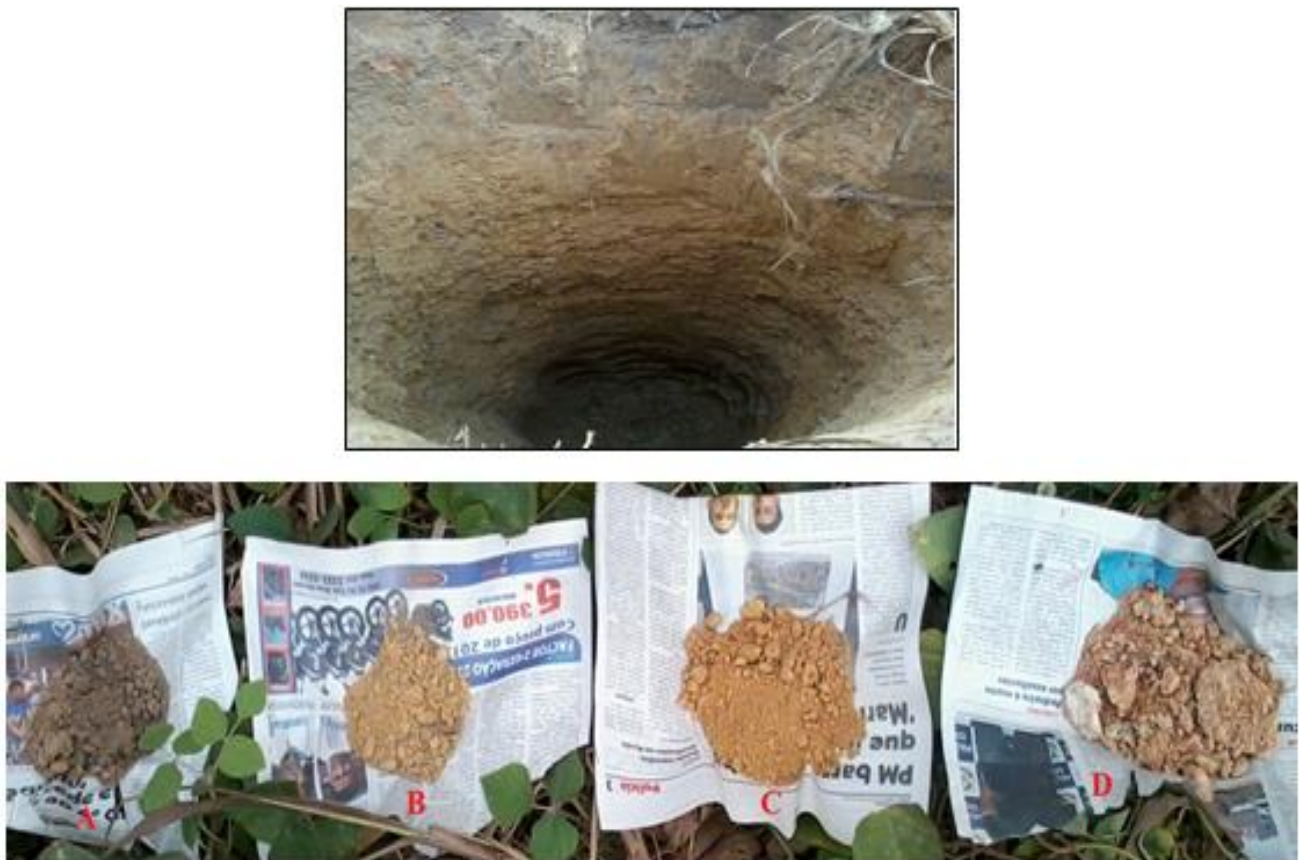
O segundo perfil de solo foi denominado de Área de Cultivo de Mandioca. Foram diferenciadas quatro seções: $A m, A B I, B g$ e $C p$ (Figura 2 e Tabela 2).

A primeira seção apresentou uma coloração cinza escura como resultado das frequentes queimadas praticadas dentro dessa área. A textura foi de 90\% de argila e 10\% de areia. Na segunda seção encontrou-se 60\% de argila e 40\% de areia, apresentando cloração amarela. Na terceira seção a textura foi de $80 \%$ de argila, 10\% de areia e 10\% de silte, de coloração brunada e com alguns mosqueados. Na quarta seção nota-se um arranjamento de cores amarelas, brancas, laranjas e vermelhas, além de pequenas concreções de óxidos de ferro característicos da plintita.

A fração de argila é de $70 \%$ e a de silte 30\%. O horizonte Am foi classificado como A moderado, o horizonte $A B \mid$ como um horizonte de transição B latossólico, o horizonte $\mathrm{Bg}$ como horizonte B glei, e o horizonte Cp como horizonte C plíntico.

Tabela 2. Caracterização morfológica de um perfil de solo em área de cultivo de mandioca no assentamento Pimenteira, São João do Araguaia-PA.

\begin{tabular}{|c|c|c|c|c|c|}
\hline \multicolumn{6}{|c|}{ Área de Cultivo de Mandioca - Plintossolo Háplico } \\
\hline Horiz. & Profund. & Cor & Textura & Estrutura & Consistência \\
\hline Am & $0-15 \mathrm{~cm}$ & $10 Y R 7 / 3$ & $\begin{array}{l}\text { Muito argilosa, } \\
\text { ligeiramente } \\
\text { pedregoso. }\end{array}$ & $\begin{array}{l}\text { Moderado a médio, } \\
\text { blocos angulares a } \\
\text { blocos subangulares. }\end{array}$ & $\begin{array}{l}\text { Pouco plástica, } \\
\text { pegajosa, macia, } \\
\text { friável. }\end{array}$ \\
\hline$A B \mid$ & $15-49 \mathrm{~cm}$ & 10 YR $6 / 6$ & $\begin{array}{c}\text { Argilosa, } \\
\text { pedregoso. }\end{array}$ & $\begin{array}{l}\text { Moderado a médio, } \\
\text { blocos angulares a } \\
\text { blocos subangulares. }\end{array}$ & $\begin{array}{c}\text { Ligeiramente plástica, } \\
\text { muito pegajosa, } \\
\text { macia, friável. }\end{array}$ \\
\hline $\mathrm{Bg}$ & $49-100 \mathrm{~cm}$ & $10 Y R$ 6/8 & $\begin{array}{l}\text { Muito argilosa, } \\
\text { moderadamente } \\
\text { pedregoso }\end{array}$ & $\begin{array}{c}\text { Médio a forte, blocos } \\
\text { subangulares a colunar. }\end{array}$ & $\begin{array}{c}\text { Muito plástica, muito } \\
\text { pegajosa, friável. }\end{array}$ \\
\hline$C p$ & $100-150 \mathrm{~cm}$ & 10 YR $8 / 8$ & $\begin{array}{l}\text { Muito argilosa, } \\
\text { pedregoso. }\end{array}$ & $\begin{array}{l}\text { Médio a forte, blocos } \\
\text { subangulares a laminar. }\end{array}$ & $\begin{array}{c}\text { Muito plástica, muito } \\
\text { pegajosa, macia, } \\
\text { friável. }\end{array}$ \\
\hline
\end{tabular}


Figura 2. Perfil de solo e camadas dos horizontes em área de cultivo de mandioca.
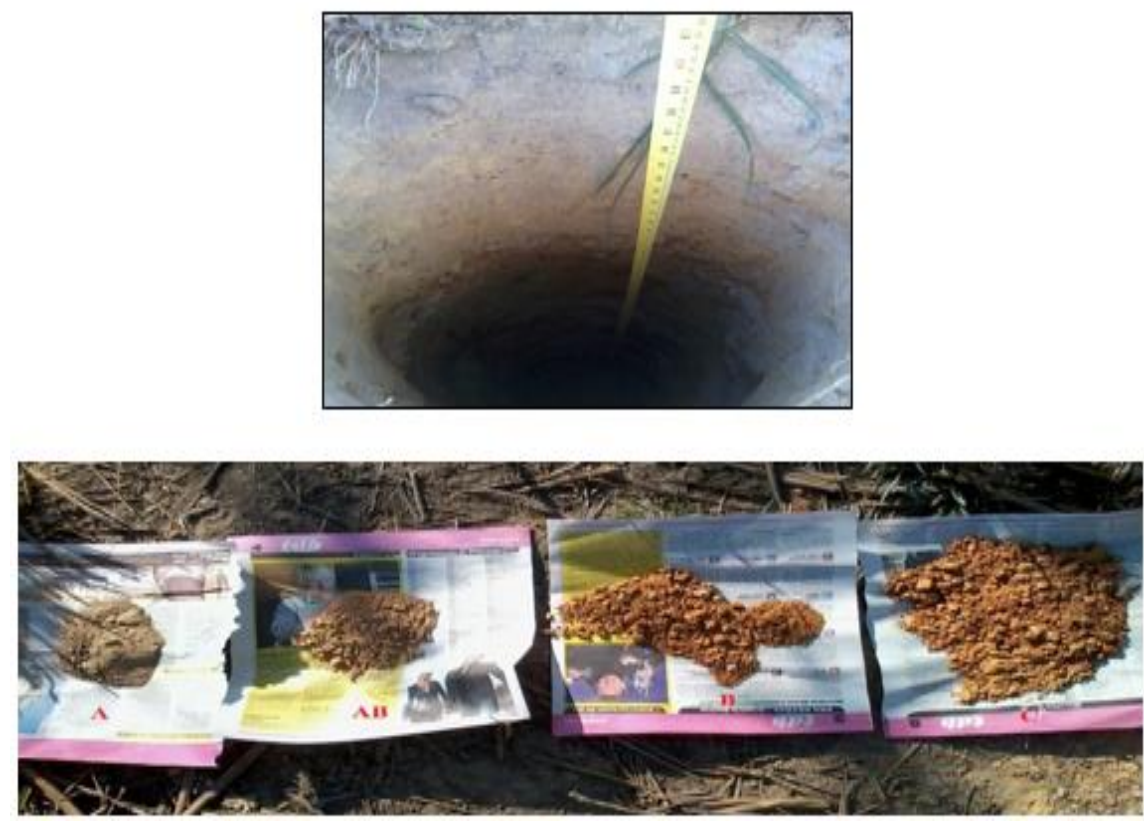

O terceiro perfil de solo foi denominado de Área de Mata Secundária. Foram diferenciadas cinco seções: $\mathrm{Am}, \mathrm{Bi} \mathrm{Cl}_{1}, \mathrm{Cl}_{2}$ e $\mathrm{Cl}_{3}$ (Figura $3 \mathrm{e}$ Tabela 3). A primeira seção apresentou uma coloração cinza escura, presenças de raízes e serapilheira. A textura foi de $60 \%$ de argila e 40\% de areia. Na segunda seção encontrou-se 70\% de argila e 30\% de areia, com grande quantidade de cascalho e apresentando coloração amarela escura e avermelhada. Na terceira seção a textura foi de $80 \%$ de argila, 10\% de areia e 10\% de silte, de coloração amarela escura e avermelhada. Na quarta seção a textura foi de $80 \%$ de argila, 20\% de silte, de coloração amarelo rosado. Na quinta seção a textura foi de $70 \%$ de argila, 30\% de silte, apresentando mosqueados de tons rosado, lilás, branco e amarelo. O horizonte Am foi classificado como A moderado, o horizonte Bi como um horizonte $\mathrm{B}$ insipiente, o horizonte $\mathrm{Cl}_{1}$ como horizonte C latossólico1, o horizonte $\mathrm{Cl}_{2}$ como horizonte $\mathrm{C}$ latossólico 2 e o horizonte $\mathrm{Cl}_{3}$ como horizonte C latossólico3. 
Tabela 3. Caracterização morfológica de um perfil de solo em área de mata secundária.

\begin{tabular}{|c|c|c|c|c|c|}
\hline \multicolumn{6}{|c|}{ Área de Mata Secundária - Plintossolo Háplico } \\
\hline Horiz. & Profund. & Cor & Textura & Estrutura & Consistência \\
\hline A & $0-13 \mathrm{~cm}$ & 7,5 YR 3/2 & Argilosa. & $\begin{array}{l}\text { Moderado a médio, } \\
\text { blocos angulares a } \\
\text { blocos subangulares. }\end{array}$ & $\begin{array}{l}\text { Ligeiramente plástica, } \\
\text { pegajosa, macia, firme. }\end{array}$ \\
\hline B & $13-26 \mathrm{~cm}$ & 10 YR 6/8 & $\begin{array}{l}\text { Muito argilosa, } \\
\text { ligeiramente } \\
\text { pedregoso. }\end{array}$ & $\begin{array}{c}\text { Médio a forte, blocos } \\
\text { subangulares a } \\
\text { colunar. }\end{array}$ & $\begin{array}{c}\text { Não plástica, muito } \\
\text { pegajosa, macia, } \\
\text { friável. }\end{array}$ \\
\hline $\mathrm{Cl}_{1}$ & $26-76 \mathrm{~cm}$ & 5YR 8/4 & $\begin{array}{c}\text { Muito argilosa, } \\
\text { moderadamente } \\
\text { pedregoso. }\end{array}$ & $\begin{array}{l}\text { Moderado a médio, } \\
\text { blocos angulares a } \\
\text { blocos subangulares. }\end{array}$ & $\begin{array}{c}\text { Pouco plástica, muito } \\
\text { pegajosa, macia, } \\
\text { friável. }\end{array}$ \\
\hline $\mathrm{Cl}_{2}$ & $76-120 \mathrm{~cm}$ & 10 YR $6 / 6$ & Muito argilosa. & $\begin{array}{l}\text { Moderado a médio, } \\
\text { blocos angulares a } \\
\text { blocos subangulares. }\end{array}$ & $\begin{array}{c}\text { Muito pegajosa, } \\
\text { plástica, macia, friável. }\end{array}$ \\
\hline $\mathrm{Cl}_{3}$ & $120-150 \mathrm{~cm}$ & 7,5 YR 6/4 & Muito argilosa. & $\begin{array}{c}\text { Médio a forte, blocos } \\
\text { subangulares a } \\
\text { laminar. }\end{array}$ & $\begin{array}{l}\text { Muito pegajosa, muito } \\
\text { plástica, macia, friável. }\end{array}$ \\
\hline
\end{tabular}

Figura 3. Amostras de solo coletadas dos horizontes de um perfil de solo em área de mata secundária.
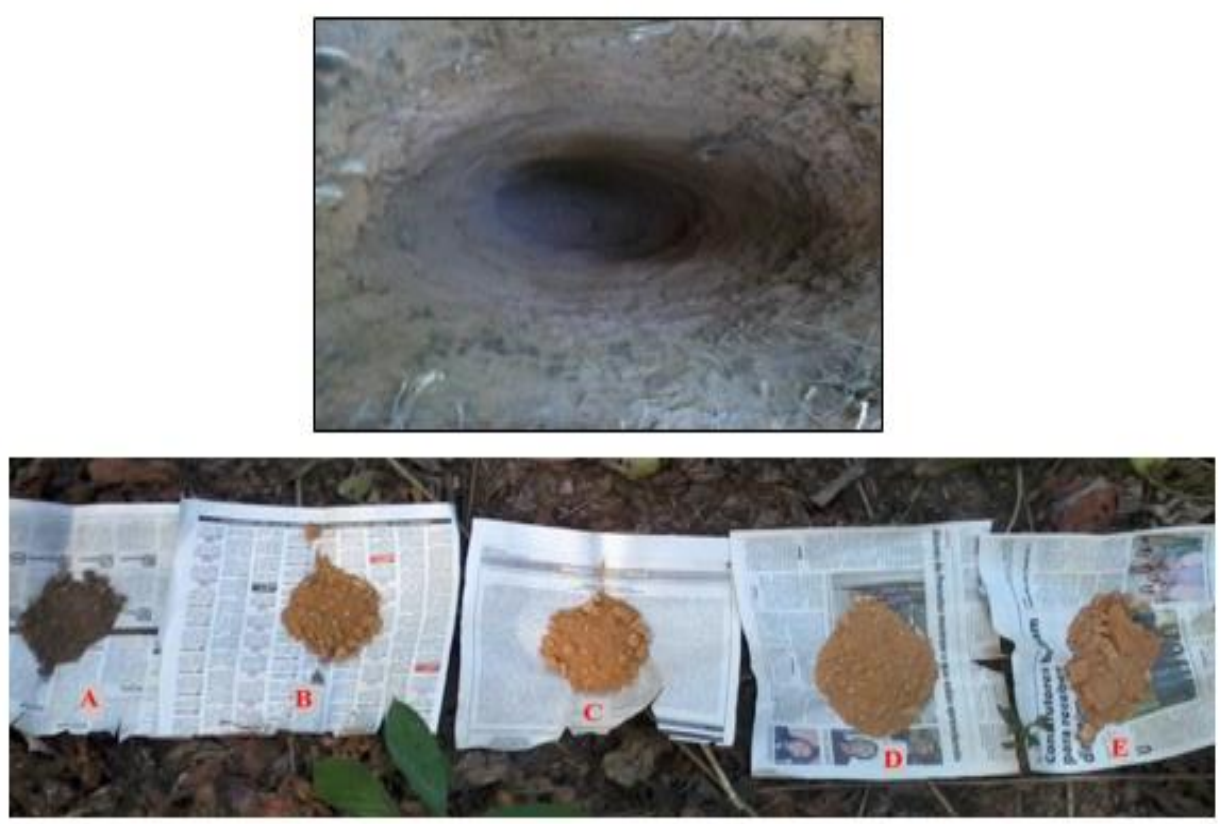

A caracterização morfológica dos perfis de solo das áreas estudadas permitiu classificar estes como
Plintossolos Háplicos. Uma vez que os Plintossolos são característicos de áreas que possuem escoamento lento de água, 
baixo teor de Fósforo e que estes apresentam grande concentração de concreções ferruginosas além da ocorrência de práticas agrícolas impostas sobre a área do sistema de produção familiar sem a percepção da conservação do solo, a exemplo do uso de queimadas, destaca-se a necessidade do manejo do solo para atender as exigências das culturas implantadas e, para a conservação do solo. Nesse sentido, o conhecimento da caracterização dos solos, através da análise dos atributos morfológicos, permite compreender as particularidades do solo, seu ambiente de ocorrência e realizar práticas de conservação do mesmo. Os resultados dessa pesquisa poderão ser utilizados como suporte para orientação técnica aos agricultores na decisão do que produzir levando em consideração primeiramente o tipo de solo e suas características, como também determinar a aptidão agrícola da terra.

\section{REFERÊNCIAS}

EMBRAPA. Centro Nacional de Pesquisa de Solos (Rio de Janeiro, RJ). Sistema brasileiro de classificação de solos. Brasília: Embrapa Produção de informação; Rio de Janeiro: Embrapa solos, 1999. 412p.

EMBRAPA. Empresa Brasileira de Pesquisa Agropecuária. Centro Nacional de Pesquisa de Solos. Sistema B rasileiro de Classificação de Solos. Brasília, 2006.

SANTOS, R. D.; LEMOS, R. C.; SANTOS, H. G.; KER, J. C.; ANJOS, L. H. C. Manual de descrição e coleta de solo no campo. 5.ed. revista e ampliada, Viçosa: Sociedade Brasileira de Ciencia de solo, 2005.

LEMOS, R. C. Manual de descrição e coleta de solo no campo. In: R.C. Lemos e R. D dos Santos. 3a Ed. Campinas. Sociedade Brasileira de Ciências do Solo, 1996.

LEPSCH, I. F. Formação e conservação dos solos. São Paulo: Oficina de Textos, 178 p. 2002.

MULLER, M. M. L.; GUIMARÃES, M. de F.; DESJARDINS, T.; MARTINS, P. F. da S. Degradação de pastagens na Região Amazônica: propriedades físicas do solo e crescimento de raízes. Pesquisa Agropecuária Brasileira. Brasília, v. 36, n. 11, p. 1409-1418, nov. 2001.

SEMA, Secretaria Estadual de Meio Ambiente. Disponível em http://www.para30graus.pa.gov.br/meteo rolo5a.htm. Acesso em 17 de setembro de 2013.

ZIMBACK, C. R. L., Formação dos solos. GEPAG, FCA-UNESP, Botucatu, 2003. 